\title{
Article \\ Comparison of the Sustainability Effects of High-Intensity Interval Exercise and Moderate-Intensity Continuous Exercise on Cognitive Flexibility
}

\author{
Shudong Tian ${ }^{1}$, Hong Mou ${ }^{1}$, Qun Fang ${ }^{1}$, Xiaoxiao Zhang ${ }^{2}$, Fanying Meng ${ }^{3}$ and Fanghui Qiu ${ }^{1, *}$ (D) \\ 1 Department of Physical Education, Qingdao University, Qingdao 266071, China; tsdtyxy@163.com (S.T.); \\ mouhong2021@126.com (H.M.); qfang_qdu@163.com (Q.F.) \\ 2 School of Psychology, Shanghai University of Sport, Shanghai 200438, China; xxzhang07282021@163.com \\ 3 Institute of Physical Education, Huzhou University, Huzhou 313000, China; 02730@zjhu.edu.cn \\ * Correspondence: qiufanghui@qdu.edu.cn
}

check for updates

Citation: Tian, S.; Mou, H.; Fang, Q.; Zhang, X.; Meng, F.; Qiu, F.

Comparison of the Sustainability Effects of High-Intensity Interval Exercise and Moderate-Intensity Continuous Exercise on Cognitive Flexibility. Int. J. Environ. Res. Public Health 2021, 18, 9631. https:// doi.org/10.3390/ijerph18189631

\section{Academic Editor:}

Amelia Guadalupe Grau

Received: 20 July 2021

Accepted: 10 September 2021

Published: 13 September 2021

Publisher's Note: MDPI stays neutral with regard to jurisdictional claims in published maps and institutional affiliations.

Copyright: (c) 2021 by the authors. Licensee MDPI, Basel, Switzerland. This article is an open access article distributed under the terms and conditions of the Creative Commons Attribution (CC BY) license (https:// creativecommons.org/licenses/by/ $4.0 /)$

\begin{abstract}
This study examined the immediate and sustained effects of high-intensity interval exercise (HIIE) and moderate-intensity continuous exercise (MICE) on cognitive flexibility in young adults. Participants $(n=56)$ engaged in (1) a session of HIIE, involving 10 sets of one-minute treadmill running at an intensity targeting $90 \%$ heart rate reserve (HRR) interspersed with self-paced walking at $50 \%$ HRR; (2) a session of MICE, involving a 20 min treadmill running at an intensity of $40-59 \%$ HRR; and (3) a control session, involving $24 \mathrm{~min}$ of resting on separate days in a counterbalanced order. Using a more-odd shifting task, cognitive flexibility was assessed before the intervention $\left(\mathrm{t}_{0}\right)$, immediately after the session $\left(t_{1}\right)$, and then at $30 \mathrm{~min}\left(t_{2}\right)$ after the session. During the more-odd shifting task, the switch cost of response time (RT) immediately after the HIIE was significantly reduced compared to that before exercise, suggesting beneficial effects on cognitive flexibility. Additionally, the impacts of HIIE were maintained for 30 min post-exercise. However, improved cognitive flexibility was not observed until $30 \mathrm{~min}$ after the MICE intervention. HIIE might represent a time-efficient approach for enhancing cognitive flexibility.
\end{abstract}

Keywords: acute exercise; cognition; more-odd shifting; time course

\section{Introduction}

Cognitive flexibility represents an ability to shift perspectives or approaches between cognitive sets by altering behavior and actions according to changing conditions [1]. Such ability has been considered an important component of executive function [2]. Cognitive flexibility is predictive of social competence and plays an essential role in problemsolving [3]. Cognitive inflexibility refers to the tendency of people to focus on their own thoughts or behaviors, thus limiting their flexible problem-solving, inhibiting the switch from current thoughts and behaviors to another [4]. Previous studies have indicated that acute exercise produces transient positive effects on executive function [5-9]. However, to our knowledge, only a few studies examined the effects of acute exercise on brain health, using improvement in cognitive flexibility as a research endpoint [5]. Most of these studies used the moderate-intensity continuous exercise (MICE) as an intervention and found improved cognitive flexibility in both young adults [10] and older adults [11]. A recent meta-analysis showed greater improvements in executive function with acute MICE in comparison to acute low intensity or high intensity continuous exercise [7]. Acute high-intensity interval exercise (HIIE) is a more novel and time-efficient physical activity [12], which is now acknowledged as a key approach for cognitive and mental health [13] and is typically associated with temporary improvements (i.e., enhanced affect, release of endorphins, increased cerebral blood flow) [14]. HIIE elicits greater benefits on health-related fitness and cognitive function in comparison to MICE $[15,16]$. Further evidence has found a positive 
effect of HIIE on cognitive flexibility [17,18]. However, no research to date has made direct comparisons between HIIE and MICE regarding the effects on cognitive flexibility.

There is mounting evidence that the improved cognitive performance induced by acute exercise can be sustained for a certain period of time. Experimental studies have shown that benefits of acute exercise on executive function such as inhibitory control [19] and working memory [20] can persist up to $30 \mathrm{~min}$ post-exercise. Studies have proposed that the sustainability of changes in cognitive performance might depend on the protocol of the preceding exercise session. For example, Tsukamoto et al. [21] have demonstrated that HIIE and MICE protocols can improve Stroop task performance (a measure of inhibitory control) immediately after exercise. Whereas the enhanced performance in the Stroop task lasts for $30 \mathrm{~min}$ after the HIIE session, the improvement associated with the MICE returns to the pre-exercise levels. In addition, various studies have shown that intermittent exercise significantly improves performance in the flanker task (a measure of inhibition control) for over $60 \mathrm{~min}$ [22], but this improvement can be preserved up to $30 \mathrm{~min}$ after the continuous exercise [19]. However, it is unclear whether there is a difference in the effect of HIIE on the sustainability of improved cognitive flexibility compared to MICE.

Acute HIIE as a more time-efficient strategy has comparable or better results than acute MICE in terms of cognitive improvement [14]. HIIE has generated significant international interest in recent years and is the second highest training trend for 2020 [23]. Accordingly, the present study aimed to examine the immediate and sustained effects of acute HIIE and acute MICE on cognitive flexibility aspect of executive function in young adults. According to previous studies which demonstrated that different exercise intensities and modalities are potential moderators of exercise-induced executive control [6], we hypothesized that HIIE would elicit a more positive and sustained improvement in cognitive flexibility compared to MICE and control sessions.

\section{Materials and Methods}

\subsection{Participants}

Sample size was calculated via the statistical power calculation $\left(G^{*}\right.$ power 3.1.9.2) on a medium effect size of 0.26 [24], using a 3 by 3 repeated measures design. Corresponding to the $\alpha$ level of 0.05 and a desired power (1- $\beta$ ) of 0.80 at the group level, a required sample size was 26 participants. To account for drop out we recruited fifty-six young adults (mean age $=20.18 \pm 1.19$ years) from the Qingdao University, China. Eligible participants should meet the following criteria: (1) right-hand dominant; (2) normal or corrected-to-normal vision and no color blindness; (3) free of any reported neurological or psychiatric diseases; (4) refrain from any moderate-to-vigorous physical exercise $24 \mathrm{~h}$ before the experiments; (5) refrain from stimulating drinks within $12 \mathrm{~h}$ of the study participation. The purpose of these inclusion criteria was to exclude the effect of moderators on the results of the experiment. All participants provided written informed consent after being informed of the potential risks. The research protocol and consents forms were approved by the Institutional Review Board of Qingdao University. Demographic characteristics and fitness data for all participants are provided in Table 1.

Table 1. Demographic characteristics and fitness data $(M \pm S D)$.

\begin{tabular}{cc}
\hline Measures & \\
\hline Anthropometric variables & \\
Sample size $(n)$ & $31 / 25$ \\
Gender (male/female) & $20.18 \pm 1.19$ \\
Age (years) & $172.99 \pm 9.07$ \\
Height $(\mathrm{cm})$ & $65.68 \pm 13.51$ \\
Weight $(\mathrm{kg})$ & $21.77 \pm 3.26$ \\
BMI $\left(\mathrm{kg} / \mathrm{m}^{2}\right)$ & \\
\hline
\end{tabular}


Table 1. Cont.

\begin{tabular}{cc}
\hline \multicolumn{2}{c}{ Measures } \\
\hline Health measures & $192.65 \pm 8.08$ \\
HRmax (bpm) & $131.20 \pm 10.07$ \\
HRR (bpm) & $164.67 \pm 10.99$ \\
Mean HIIE HR (bpm) & $136.38 \pm 5.07$ \\
Mean MICE HR (bpm) & $16.03 \pm 1.51$ \\
HIIE RPE & $13.00 \pm 1.69$ \\
MICE RPE &
\end{tabular}

Note: $\mathrm{BMI}$ = body mass index; $\mathrm{RPE}$ = ratings of perceived exertion; $\mathrm{HR}=$ heart rate; $\mathrm{HRR}$ = heart rate reserve.

\subsection{More-Odd Shifting Task}

Cognitive flexibility was evaluated by the more-odd shifting task [25], which consisted of a series of digits from either 1 to 4 or 6 to 9 . The task was generated by a computer program using E-Prime 2.0 (Psychology Software Tools Inc., Pittsburgh, PA, USA) and was displayed on a 15.6-inch monitor, the distance of which was $80 \mathrm{~cm}$ away from the participants.

All digits were presented for $2000 \mathrm{~ms}$ and separated by $1000 \mathrm{~ms}$ inter-stimulus intervals. The more-odd shifting task consisted of three types of blocks. Block A involves 16 non-switching trials in which the participants were asked to answer whether the number in black was greater or less than 5. Block B involves 16 non-switching trials in which the participants were asked to identify whether the number in green was odd or even. Block C consisted of 32 switching trials which requested the participants to determine the magnitude of the digit in black and the parity of the digit in green. Participants responded to each stimulus by pressing " $\mathrm{F}$ " or " $\mathrm{J}$ " button with their left or right index finger as quickly and accurately as possible. The task consisted of 2 switching blocks and 4 non-switching blocks in a counterbalanced order (i.e., ABCCBA). Response time (RT) and accuracy of the task were recorded. The mean RT from response-correct trials and accuracy were calculated for each trial type (switch and non-switch). In addition, we assessed the switch cost which was defined as the difference of RTs between the switching trials (i.e., block $\mathrm{C}$ ) and the non-switching trials (i.e., block A and B) [26].

\subsection{Exercise Protocols}

Each participant was requested to attend three interventions of HIIE, MICE and control. Direct measurements of maximal heart rate (HRmax) is used by the graded exercise test (GXT) $[27,28]$. Heart rate reserve (HRR) was calculated based on HRmax to determine exercise intensity. The initial speed of the test was $8.5 \mathrm{~km} / \mathrm{h}$ with a degree of $3 \%$, then the treadmill speed was increased by $0.5 \mathrm{~km} / \mathrm{h}$ every $1 \mathrm{~min}$ and the grade was kept constant until participants became volitional exhausted. Maximum volitional exhaustion was identified when the participant achieved at least two of the three following criteria: (a) a plateau in heart rate resulting in no longer rising with an increase in workload, (b) a peak HR $\geq$ age-predicted HRmax $208-(0.7 \times$ age) [29], and (c) Ratings of perceived exertion (RPE) $\geq 17$. Resting heart rate (RHR) was obtained while seated using a Polar H10 heart rate strap (Polar, Kemple, Finland). Exercise intensity was appropriately tailored to each individual based on HRR. HRR corresponds to a defined percentage of the difference between HRmax and resting HR (HRR = HRmax - RHR) [30]. During the HIIE session, participants completed 10 bouts of repeated $1 \mathrm{~min}$ runs on a treadmill at an intensity targeting $90 \%$ HRR ( $90 \%$ HRR + RHR), interspersed with 1 min of self-paced walking at $50 \%$ HRR $(50 \%$ HRR + RHR) [15,30]. During the MICE session, participants completed $20 \mathrm{~min}$ of running on a treadmill at an intensity of $40 \%$ to $59 \%$ HRR ( $40-59 \%$ HRR + RHR) [11,30]. Each exercise began with a 2 min warm-up and ended with a 2 min cool-down [15]. During the control session, participants sat quietly on a chair and read a book for $24 \mathrm{~min}$ [11]. Before each session, each participant was fitted with a Polar H10 heart rate strap, which was kept fitted until the end of each intervention. The protocols were illustrated in Figure 1. 
(a) HIIE

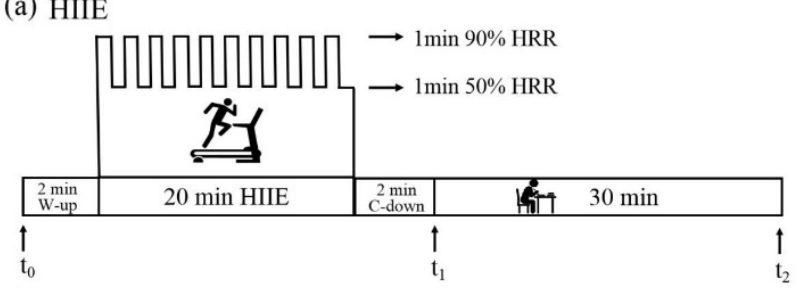

(b) MICE

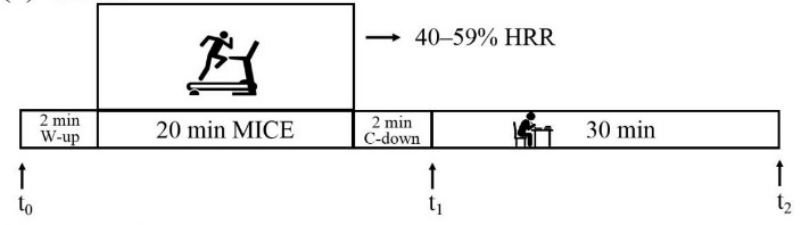

(c) Control

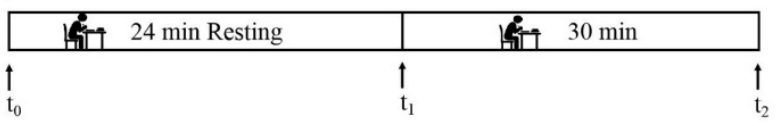

Figure 1. Time courses of HIIE (a), MICE (b) and control (c) sessions. Cognitive flexibility was assessed before the intervention $\left(t_{0}\right)$, and immediately $\left(t_{1}\right)$ and $30 \mathrm{~min}\left(t_{2}\right)$ after the intervention. HIIE: high-intensity interval exercise. MICE: moderate-intensity continuous exercise. W-up: warm-up. C-down: cool-down.

\subsection{Procedure}

The study was conducted using a within-subjects, repeated-measures design. It included one HIIE session, one MICE session, and one control session conducted in a counterbalanced order. These three sessions were separated by at least one week and were completed at approximately the same time of the day. Before the experiment, participants completed the informed consent, the demographic sheet and the Physical Activity Readiness Questionnaire (PAR-Q) [31]. The purpose of PAR-Q was to exclude the potential risks. Exercise preparticipation health screening was performed for all participants to identify individuals who may be at increased risk of exercise-related sudden cardiac death and/or acute myocardial infarction [32]. Participants were instructed to practice 20 trials until $85 \%$ accuracy for the trial block was achieved before each experiment. In addition, all participants were asked to complete the shifting task before the intervention $\left(t_{0}\right)$ and at two time points after the intervention, including immediately $\left(t_{1}\right), 30 \mathrm{~min}\left(\mathrm{t}_{2}\right)$. Ratings of perceived exertion (RPE) [33] were assessed at 5 min intervals during HIIE and MICE interventions and average RPE was computed. According to the American College of Sports Medicine (ACSM) guidelines state that the RPE of high- and moderate-intensity exercise should fall within 14-17 and 12-13 RPE, respectively [34]. The purpose of measuring the RPE score is to compare it with the RPE score of the ACSM guidelines for exact exercise intensity. Participants received $150 \mathrm{RMB}$ at the end of the entire session, and were told the detailed purpose and expectations of this research.

\subsection{Statistical Analysis}

For the RT analysis, incorrect trials were first removed and then an outlier correction was performed by separately excluding trials with an RT of 3 standard deviations from the mean for each task condition (switch and non-switch). Response accuracy and RTs were analyzed using a 3 (session: HIIE, MICE, and control) $\times 3$ (time point: $t_{0}, t_{1}$ and $\left.t_{2}\right) \times 2$ (task condition: switch and non-switch) three-way repeated-measures analysis of variance (RM ANOVA). Switch cost was examined separately for RT (switch - non-switch) [17] using a 3 (session: HIIE, MICE, and control) $\times 3$ (time point: $t_{0}, t_{1}$ and $t_{2}$ ) RM ANOVA. Mauchly's test was used to examine spherical data, and the Greenhouse-Geisser correction was used to analyze non-spherical data. The Shapiro-Wilk normality test was applied to confirm normal distribution of data before the ANOVA. Paired-samples $t$-test with Bonferroni adjustments for multiple comparisons were applied for post hoc analysis [11]. The $p$-value 
of 0.05 was selected as the cutoff point for statistical significance. Effect sizes were presented by partial squared $\left(\eta^{2}\right)$ values as measures for main and interaction effects. All statistical analyses were performed by the Statistical Package for Social Sciences software (SPSS version 25.0, Chicago, IL, USA).

\section{Results}

\subsection{Response Time}

The there-way RM ANOVA revealed a significant interaction for time point by task condition $\left(F_{(2,56)}=11.96, p<0.001, \eta^{2}=0.42\right)$, and time point by session $\left(F_{(4,54)}=9.71\right.$, $\left.p<0.001, \eta^{2}=0.42\right)$. In addition, there was a significant session $\times$ time point $\times$ task condition interaction effect $\left(F_{(4,54)}=3.16, p=0.021, \eta^{2}=0.20\right)$. Comparisons in the interactions between session, time point, and task condition revealed that RT in the non-switching condition was significantly slower before the MICE intervention compared to immediately $(p=0.001)$ and $30 \mathrm{~min}(p=0.006)$ after the MICE intervention. For the HIIE intervention, RT in non-switching condition was significantly slower before the intervention compared to $30 \mathrm{~min}$ after intervention $(p<0.001)$. RT for the switching condition immediately after HIIE was significantly shortened compared to that before HIIE, and this shortened RT was sustained during the $30 \mathrm{~min}$ post-exercise recovery $(p<0.001$ for all). Similar results were found after MICE, with a decreased RT immediately after MICE, and this improvement lasted for up to $30 \mathrm{~min}$ after exercise $(p<0.001$ for all). There was a significant main effect for time point $\left(F_{(2,54)}=32.40, p<0.001, \eta^{2}=0.55\right)$. The post hoc test showed that RT was significantly slower before the intervention $(666.84 \pm 111.81 \mathrm{~ms})$ compared with immediately $(637.26 \pm 109.63 \mathrm{~ms}, p<0.001)$ and $30 \mathrm{~min}(630.10 \pm 103.96 \mathrm{~ms}, p<0.001)$ after the intervention. A significant main effect of task condition was identified $\left(F_{(1,57)}=114.85\right.$, $\left.p<0.001, \eta^{2}=0.67\right)$, with longer RTs in the switching condition $(715.10 \pm 127.44 \mathrm{~ms})$ compared with the non-switching condition (574.37 $\pm 89.49 \mathrm{~ms})$. No significant differences were detected among time points for switching and non-switching trials in the control session ( $p>0.45$ for all). No main effect for session $\left(F_{(2,54)}=0.25, p=0.78, \eta^{2}=0.009\right)$ or interaction of session by task condition $\left(F_{(2,54)}=0.54, p=0.59, \eta^{2}=0.02\right)$ was observed (Figure 2a,b).
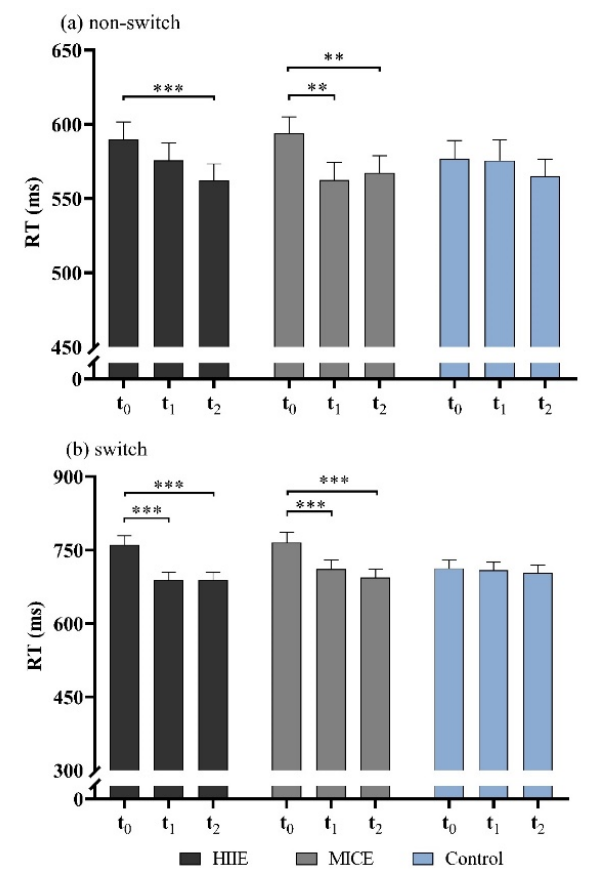

Figure 2. RTs for non-switching condition (a) and switching condition (b) in the more-odd shifting task. HIIE: high-intensity interval exercise; MICE: moderate-intensity continuous exercise. $\left(* * p<0.01,{ }^{* * *} p<0.001\right)$. 


\subsection{Switch Cost}

The two-way RM ANOVA revealed a significant effect for interaction of session by time point $\left(F_{(4,54)}=3.16, p=0.021, \eta^{2}=0.20\right)$. The interaction contrasts revealed that switch cost was significantly lower immediately $(p=0.001)$ and $30 \mathrm{~min}(p=0.001)$ after the HIIE intervention compared to that before the HIIE intervention and was significantly lower 30 min $(p<0.001)$ after the MICE intervention compared to before the MICE intervention. There was a significant main effect for time point $\left(F_{(2,56)}=11.96, p<0.001, \eta^{2}=0.42\right)$. The post hoc test showed that the switch cost was significantly higher before the intervention compared to immediately $(p=0.001)$ and $30 \mathrm{~min}(p<0.001)$ after the intervention. No significant difference was found in the switch cost between the time points in the control session ( $p>0.9$ for all) (Figure 3).

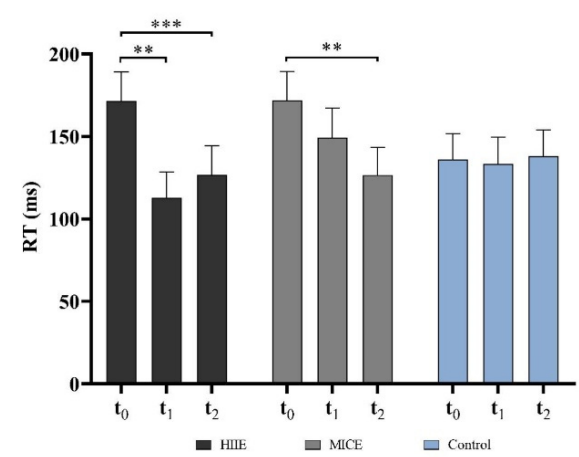

Figure 3. Switch cost of the more-odd shifting task. $\left({ }^{* *} p<0.01,{ }^{* * *} p<0.001\right)$.

\subsection{Accuracy}

The there-way ANOVA revealed a significant main effect on task condition $\left(F_{(1,55)}=6.88\right.$, $\left.p=0.013, \eta^{2}=0.16\right)$, with greater mean accuracy for the non-switching $(93.69 \pm 6.29 \%)$ condition than the switching condition $(92.04 \pm 6.64 \%)$. There was a significant interaction between session and task condition $\left(F_{(1,55)}=6.88, p=0.013, \eta^{2}=0.16\right)$. No significant result was identified in the main effects of session $\left(F_{(2,54)}=0.51, p=0.60\right)$ or time point $\left(F_{(2,54)}=0.001, p=0.99\right)$ or interaction effects of time point $\times$ task condition $\left(F_{(2,54)}=0.45\right.$, $p=0.64)$, session $\times$ time point $\left(F_{(4,52)}=0.21, p=0.93\right)$ or session $\times$ time point $\times$ task condition $\left(F_{(4,52)}=0.44, p=0.78\right)$ (Figure $\left.4 \mathrm{a}, \mathrm{b}\right)$.

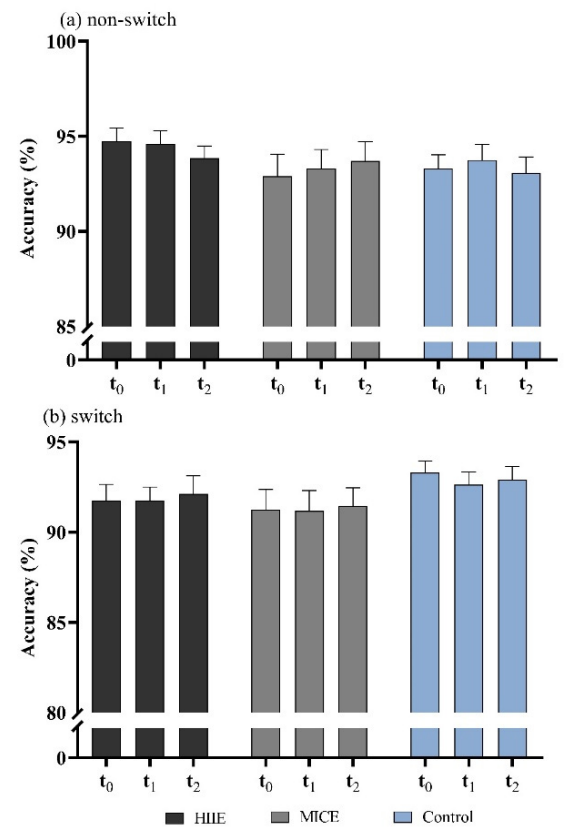

Figure 4. Accuracy for non-switching trials (a) and switching trials $(\mathbf{b})$ in the more-odd shifting task. 


\section{Discussion}

This study evaluated the sustained effects of acute treadmill-based HIIE and MICE on cognitive flexibility in young adults. Participants performed better in a more-odd shifting task, with the improved performance lasting for at least $30 \mathrm{~min}$ after the intervention. The improvement in cognitive flexibility was only detected $30 \mathrm{~min}$ after the end of the MICE session. These findings suggest that both HIIE and MICE can improve cognitive flexibility. HIIE may be a more effective strategy than MICE in improving cognitive flexibility.

Exercise as a stressor can promote physiological and psychological arousal [21,35], and increase oxygen and blood flow to the brain [36], which can optimize the allocation of cognitive resources and promote the efficiency of cognitive processing [37]. This study showed that participants performed better in the cognitive flexibility task after the HIIE intervention, compared to the resting session. The findings are consistent with previous studies [17,18]. Using a modification of the number-letter task, Berse et al. [17] showed that the switch cost of RT generally declined and that the accuracy of the switch and non-switch significantly increased after HIIE, compared with the non-significant changes in the resting condition. However, comparable facilitation in cognitive flexibility was not observed in the cognitive tests immediately following MICE intervention, which was also substantiated by previous studies. For example, Schwarck et al. [38] found that no acute effects of MICE on cognitive flexibility were observed in young adults. In contrast, Chen et al. [11] tested the effects of MICE on switching task performance and found that 20 min of MICE was effective in improving cognitive flexibility in older adults. The inconsistencies related to the effects of acute exercise on cognitive flexibility may be attributed to the characteristics of participants, types of task paradigms assessed, duration of exercise intervention, and the time at which the cognitive task was administered $[6,11]$. Collectively, our findings suggest that in young adults, acute effects on cognitive flexibility are favorable to HIIE over MICE.

The present study demonstrated that the improved cognitive flexibility identified immediately after HIIE was sustained for at least $30 \mathrm{~min}$. This result is comparable to the previous research which has examined other aspects of executive function including inhibition control [21,39] and working memory [20]. While sharing some similarities, the subdomains of executive control do have distinguishing characteristics. Martínez-Díaz et al. [20] reported similar improvements in the work memory assessed by the digit spans test and the improvement in working memory was maintained for $30 \mathrm{~min}$ after the HIIE session. Cooper et al. [39] examined high-intensity intermittent games-based activity on inhibitory control using a Stroop task and indicated that the benefits of HIIE can last up to $45 \mathrm{~min}$ after exercise. Collectively, not only does HIIE have a sustained effect on inhibitory control and working memory, but also has a delayed effect on cognitive flexibility. Cognitive flexibility performance was improved $30 \mathrm{~min}$ after the MICE intervention, rather than immediately, as indicated by lower switch cost. This result is consistent with the conclusions of a metaanalysis, which reported that effects of moderate intensity exercise on executive function were more pronounced after a delay exercise than immediately following the exercise [6]. Furthermore, Kamijo et al. [40] conducted a 20 min MICE intervention and found that cognitive performance improved within $30 \mathrm{~min}$ after the intervention. Decreased intraindividual variability $30 \mathrm{~min}$ after MICE relative to before exercise may have contributed to this result [40]. Intraindividual variability is regarded as reflecting the ability to monitor and maintain consistency in task performance during acute cognitive effort [41]. Thus, the decreased intraindividual variability $30 \mathrm{~min}$ after MICE is likely to be indicative of upregulation of cognitive flexibility to maintain task performance over the entire course of the shifting task.

In addition, our findings reflect that the positive effect of HIIE on cognitive flexibility is disproportionately larger in task conditions with greater cognitive demands (switch trials). Evidence has shown that selective cognitive improvements occur following acute exercise, with more significant benefits occurring for tests that require greater cognitive demands [16]. Several recent studies have confirmed that acute exercise has a disproportionately larger effect on performance of tasks involving higher executive function demands, including 
inhibitory control tasks [16,42] and working memory tasks [43]. Using a flanker task, Kao et al. [16] found that HIIE increased response accuracy selectively for incongruent trials. As for the RT, Cooper et al. [39] revealed that higher complex levels of Stroop task was improved after the HIIE intervention. Our results confirm previous findings that conditions with larger cognitive demands improve more significantly after HIIE.

Acute exercise may improve task performance through different mechanisms. It is understood that exercise induces an increase in brain-derived neurotrophic factor (BDNF) as a possible mechanism leading to improved cognitive flexibility [18]. BDNF is an activity-dependent protein that may also influence functional connectivity by increasing synaptogenesis and dendritic spine density, thus improving cognitive performance by increasing synaptic plasticity [44]. Robust expression of BDNF in the hippocampus is crucial in mediating the enhancement of exercise-induced cognitive flexibility [18]. Saucedo Marquez et al. [45] revealed that the HIIE protocol $(10 \times 1 \mathrm{~min}$ bouts at $90 \%$ of maximal HR, alternating with $1 \mathrm{~min}$ rest for a total duration of $20 \mathrm{~min}$ ) is a more effective intervention for elevating BDNF levels than MICE. Higher BDNF levels may account for the immediately improved cognitive flexibility performance after HIIE intervention compared to MICE. Furthermore, increased levels of cerebral cortex activation may be another factor for the cognitive boosting effect of exercise. Previous studies have suggested that improved executive function (including cognitive flexibility) after acute exercise was associated with increased activity in left-dorsolateral prefrontal cortex and parietal regions of the brain [46,47], including increasing oxygen-rich blood flow to the brain [48] and enhancing psychological arousal level [47]. Tsukamoto et al. [21] demonstrated that Felt Arousal Scale [49] derived arousal level was significantly higher for HIIE than MICE immediately after the exercise. Therefore, HIIE might more efficiently modulate the central nervous system activation and better improve cognitive performance relative to MICE.

The current study has a few limitations that need to be taken into account in interpreting the findings. First, our study design could have resulted in practice effects due to the number of testing sessions. However, we counterbalanced the sequence of sessions and extended the interval between sessions to at least 7 days to minimize such effect by spreading any remaining practice effects across all conditions. Second, the 20-min duration and intensity of exercise selected for this study may be appropriate for young adults, but may need to be adjusted in people of other age levels or fitness levels. Third, this study compared the acute effects of HIIE and MICE on cognitive flexibility for only $60 \mathrm{~min}$. In future studies we will investigate the effects with chronic or acute HIIE on cognitive flexibility over a longer period of time at least for few days.

\section{Conclusions}

The present investigation indicated the sustained effect of treadmill-based acute HIIE and MICE on cognitive flexibility in young adults. Specifically, the MICE intervention significantly facilitated cognitive flexibility within $30 \mathrm{~min}$ after exercise. However, the enhanced cognitive flexibility by the HIIE intervention was not only reflected immediately after exercise, but also lasted for $30 \mathrm{~min}$ after exercise. Thus, HIIE represents a time-efficient approach for enhancing cognitive performance. It is recommended to consider HIIE an effective approach to improve performance that relies on cognitive flexibility. By using HIIE to separate a long-hour task into a few intervals, people may achieve higher efficiency in the workplace or at school. Therefore, the current study implies practical values that should raise awareness of the public.

Author Contributions: Conceptualization, S.T., Q.F. and F.Q.; methodology, S.T., H.M. and F.Q.; formal analysis, S.T. and F.Q.; investigation, S.T., H.M. and F.Q.; writing-original draft preparation, S.T., H.M. and F.Q.; writing-review and editing, S.T., Q.F., F.M., X.Z. and F.Q. All authors have read and agreed to the published version of the manuscript.

Funding: This research received no external funding. 
Institutional Review Board Statement: The study was conducted according to the guidelines of the Declaration of Helsinki, and approved by the Medical Ethics Committee of the Affiliated Hospital of Qingdao University.

Informed Consent Statement: Informed consent was obtained from all subjects involved in the study.

Data Availability Statement: The data presented in this study are available on request from the corresponding author.

Conflicts of Interest: The authors declare no conflict of interest.

\section{References}

1. Diamond, A. Executive functions. Annu. Rev. Psychol. 2013, 64, 135-168. [CrossRef] [PubMed]

2. De Greeff, J.W.; Bosker, R.J.; Oosterlaan, J.; Visscher, C.; Hartman, E. Effects of physical activity on executive functions, attention and academic performance in preadolescent children: A meta-analysis. J. Sci. Med. Sport 2018, 21, 501-507. [CrossRef] [PubMed]

3. Uddin, L.Q. Cognitive and behavioural flexibility: Neural mechanisms and clinical considerations. Nat. Rev. Neurosci. 2021, 22, 167-179. [CrossRef]

4. Ozsivadjian, A.; Hollocks, M.J.; Magiati, I.; Happé, F.; Baird, G.; Absoud, M. Is cognitive inflexibility a missing link? The role of cognitive inflexibility, alexithymia and intolerance of uncertainty in externalising and internalising behaviours in young people with autism spectrum disorder. J. Child Psychol. Psychiatry Allied Discip. 2021, 62, 715-724. [CrossRef] [PubMed]

5. Verburgh, L.; Königs, M.; Scherder, E.J.; Oosterlaan, J. Physical exercise and executive functions in preadolescent children, adolescents and young adults: A meta-analysis. Br. J. Sports Med. 2014, 48, 973-979. [CrossRef] [PubMed]

6. Chang, Y.K.; Labban, J.D.; Gapin, J.I.; Etnier, J.L. The effects of acute exercise on cognitive performance: A meta-analysis. Brain Res. 2012, 1453, 87-101. [CrossRef]

7. Ludyga, S.; Gerber, M.; Brand, S.; Holsboer-Trachsler, E.; Pühse, U. Acute effects of moderate aerobic exercise on specific aspects of executive function in different age and fitness groups: A meta-analysis. Psychophysiology 2016, 53, 1611-1626. [CrossRef] [PubMed]

8. Moreau, D.; Chou, E. The Acute Effect of High-Intensity Exercise on Executive Function: A Meta-Analysis. Perspect. Psychol. Sci. A J. Assoc. Psychol. Sci. 2019, 14, 734-764. [CrossRef]

9. Northey, J.M.; Cherbuin, N.; Pumpa, K.L.; Smee, D.J.; Rattray, B. Exercise interventions for cognitive function in adults older than 50: A systematic review with meta-analysis. Br. J. Sports Med. 2018, 52, 154-160. [CrossRef]

10. Bae, S.; Masaki, H. Effects of Acute Aerobic Exercise on Cognitive Flexibility Required During Task-Switching Paradigm. Front. Hum. Neurosci. 2019, 13, 260. [CrossRef]

11. Chen, F.T.; Etnier, J.L.; Wu, C.H.; Cho, Y.M.; Hung, T.M.; Chang, Y.K. Dose-Response Relationship between Exercise Duration and Executive Function in Older Adults. J. Clin. Med. 2018, 7, 279. [CrossRef]

12. Eddolls, W.T.B.; McNarry, M.A.; Stratton, G.; Winn, C.O.N.; Mackintosh, K.A. High-Intensity Interval Training Interventions in Children and Adolescents: A Systematic Review. Sports Med. 2017, 47, 2363-2374. [CrossRef] [PubMed]

13. Costigan, S.A.; Eather, N.; Plotnikoff, R.C.; Hillman, C.H.; Lubans, D.R. High-Intensity Interval Training for Cognitive and Mental Health in Adolescents. Med. Sci. Sports Exerc. 2016, 48, 1985-1993. [CrossRef] [PubMed]

14. Leahy, A.A.; Mavilidi, M.F.; Smith, J.J.; Hillman, C.H.; Eather, N.; Barker, D.; Lubans, D.R. Review of High-Intensity Interval Training for Cognitive and Mental Health in Youth. Med. Sci. Sports Exerc. 2020, 52, 2224-2234. [CrossRef]

15. Kao, S.C.; Drollette, E.S.; Ritondale, J.P.; Khan, N.A.; Hillman, C.H. The acute effects of high-intensity interval training and moderateintensity continuous exercise on declarative memory and inhibitory control. Psychol. Sport Exerc. 2018, 38, 90-99. [CrossRef]

16. Kao, S.C.; Westfall, D.R.; Soneson, J.; Gurd, B.; Hillman, C.H. Comparison of the acute effects of high-intensity interval training and continuous aerobic walking on inhibitory control. Psychophysiology 2017, 54, 1335-1345. [CrossRef] [PubMed]

17. Berse, T.; Rolfes, K.; Barenberg, J.; Dutke, S.; Kuhlenbäumer, G.; Völker, K.; Winter, B.; Wittig, M.; Knecht, S. Acute physical exercise improves shifting in adolescents at school: Evidence for a dopaminergic contribution. Front. Behav. Neurosci. 2015, 9, 196. [CrossRef]

18. Kujach, S.; Olek, R.A.; Byun, K.; Suwabe, K.; Sitek, E.J.; Ziemann, E.; Laskowski, R.; Soya, H. Acute Sprint Interval Exercise Increases Both Cognitive Functions and Peripheral Neurotrophic Factors in Humans: The Possible Involvement of Lactate. Front. Neurosci. 2020, 13, 1455. [CrossRef]

19. Lambrick, D.; Stoner, L.; Grigg, R.; Faulkner, J. Effects of continuous and intermittent exercise on executive function in children aged 8-10 years. Psychophysiology 2016, 53, 1335-1342. [CrossRef]

20. Martínez-Díaz, I.C.; Escobar-Muñoz, M.C.; Carrasco, L. Acute Effects of High-Intensity Interval Training on Brain-Derived Neurotrophic Factor, Cortisol and Working Memory in Physical Education College Students. Int. J. Environ. Res. Public Health 2020, 17, 8216. [CrossRef]

21. Tsukamoto, H.; Suga, T.; Takenaka, S.; Tanaka, D.; Takeuchi, T.; Hamaoka, T.; Isaka, T.; Hashimoto, T. Greater impact of acute high-intensity interval exercise on post-exercise executive function compared to moderate-intensity continuous exercise. Physiol. Behav. 2016, 155, 224-230. [CrossRef] [PubMed]

22. Ludyga, S.; Pühse, U.; Lucchi, S.; Marti, J.; Gerber, M. Immediate and sustained effects of intermittent exercise on inhibitory control and task-related heart rate variability in adolescents. J. Sci. Med. Sport 2019, 22, 96-100. [CrossRef] [PubMed]

23. Thompson, W.R. Worldwide survey of fitness trends for 2020. ACSM Health Fit. J. 2019, 23, 8-10. [CrossRef] 
24. Naderi, A.; Shaabani, F.; Esmaeili, A.; Salman, Z.; Degens, H. Effects of low and moderate acute resistance exercise on executive function in community-living older adults. Sport Exerc. Perform. Psychol. 2018, 8, 106-122. [CrossRef]

25. Hillman, C.H.; Kramer, A.F.; Belopolsky, A.V.; Smith, D.P. A cross-sectional examination of age and physical activity on performance and event-related brain potentials in a task switching paradigm. Int. J. Psychophysiol. Off. J. Int. Organ. Psychophysiol. 2006, 59, 30-39. [CrossRef]

26. Chen, A.G.; Yan, J.; Yin, H.C.; Pan, C.Y.; Chang, Y.K. Effects of acute aerobic exercise on multiple aspects of executive function in preadolescent children. Psychol. Sport Exerc. 2014, 15, 627-636. [CrossRef]

27. Ferguson, B. ACSM's Guidelines for Exercise Testing and Prescription 9th Ed. 2014. J. Can. Chiropr. Assoc. 2014, $58,328$.

28. Mekari, S.; Dupuy, O.; Martins, R.; Evans, K.; Kimmerly, D.S.; Fraser, S.; Neyedli, H.F. The effects of cardiorespiratory fitness on executive function and prefrontal oxygenation in older adults. GeroScience 2019, 41, 681-690. [CrossRef]

29. Ludyga, S.; Gerber, M.; Mücke, M.; Brand, S.; Weber, P.; Brotzmann, M.; Pühse, U. The Acute Effects of Aerobic Exercise on Cognitive Flexibility and Task-Related Heart Rate Variability in Children With ADHD and Healthy Controls. J. Atten. Disord. 2020, 24, 693-703. [CrossRef]

30. Stavrinos, E.L.; Coxon, J.P. High-intensity Interval Exercise Promotes Motor Cortex Disinhibition and Early Motor Skill Consolidation. J. Cogn. Neurosci. 2017, 29, 593-604. [CrossRef]

31. Thomas, S.; Reading, J.; Shephard, R.J. Revision of the Physical Activity Readiness Questionnaire (PAR-Q). Can. J. Sport Sci. 1992, $17,338-345$.

32. Riebe, D.; Franklin, B.A.; Thompson, P.D.; Garber, C.E.; Whitfield, G.P.; Magal, M.; Pescatello, L.S. Updating ACSM's Recommendations for Exercise Preparticipation Health Screening. Med. Sci. Sports Exerc. 2015, 47, 2473-2479. [CrossRef]

33. Borg, G. Perceived exertion as an indicator of somatic stress. Scand. J. Rehabil. Med. 1970, 2, 92-98. [PubMed]

34. Medicine, A.C.o.S. ACSM's Guidelines for Exercise Testing and Prescription, 9th ed.; Lippincott, Williams \& Wilkins: Philadelphia, PA, USA, 2014.

35. Stork, M.J.; Gibala, M.J.; Martin Ginis, K.A. Psychological and Behavioral Responses to Interval and Continuous Exercise. Med. Sci. Sports Exerc. 2018, 50, 2110-2121. [CrossRef]

36. Wheeler, M.J.; Dunstan, D.W.; Smith, B.; Smith, K.J.; Scheer, A.; Lewis, J.; Naylor, L.H.; Heinonen, I.; Ellis, K.A.; Cerin, E.; et al. Morning exercise mitigates the impact of prolonged sitting on cerebral blood flow in older adults. J. Appl. Physiol. 2019, 126, 1049-1055. [CrossRef]

37. Chang, Y.K.; Alderman, B.L.; Chu, C.H.; Wang, C.C.; Song, T.F.; Chen, F.T. Acute exercise has a general facilitative effect on cognitive function: A combined ERP temporal dynamics and BDNF study. Psychophysiology 2017, 54, 289-300. [CrossRef]

38. Schwarck, S.; Schmicker, M.; Dordevic, M.; Rehfeld, K.; Müller, N.; Müller, P. Inter-Individual Differences in Cognitive Response to a Single Bout of Physical Exercise-A Randomized Controlled Cross-Over Study. J. Clin. Med. 2019, 8, 1101. [CrossRef] [PubMed]

39. Cooper, S.B.; Dring, K.J.; Morris, J.G.; Sunderland, C.; Bandelow, S.; Nevill, M.E. High intensity intermittent games-based activity and adolescents' cognition: Moderating effect of physical fitness. BMC Public Health 2018, 18, 603. [CrossRef] [PubMed]

40. Kamijo, K.; Abe, R. Aftereffects of Cognitively Demanding Acute Aerobic Exercise on Working Memory. Med. Sci. Sports Exerc. 2019, 51, 153-159. [CrossRef] [PubMed]

41. Bielak, A.A.M.; Brydges, C.R. Can Intraindividual Variability in Cognitive Speed Be Reduced by Physical Exercise? Results From the LIFE Study. J. Gerontology. Ser. B Psychol. Sci. Soc. Sci. 2019, 74, 1335-1344. [CrossRef]

42. Tian, S.; Mou, H.; Qiu, F. Sustained Effects of High-Intensity Interval Exercise and Moderate-Intensity Continuous Exercise on Inhibitory Control. Int. J. Environ. Res. Public Health 2021, 18, 2687. [CrossRef] [PubMed]

43. Hsieh, S.S.; Chang, Y.K.; Hung, T.M.; Fang, C.L. The effects of acute resistance exercise on young and older males' working memory. Psychol. Sport Exerc. 2016, 22, 286-293. [CrossRef]

44. Vaynman, S.S.; Ying, Z.; Yin, D.; Gomez-Pinilla, F. Exercise differentially regulates synaptic proteins associated to the function of BDNF. Brain Res. 2006, 1070, 124-130. [CrossRef] [PubMed]

45. Saucedo Marquez, C.M.; Vanaudenaerde, B.; Troosters, T.; Wenderoth, N. High-intensity interval training evokes larger serum BDNF levels compared with intense continuous exercise. J. Appl. Physiol. 2015, 119, 1363-1373. [CrossRef]

46. Derrfuss, J.; Brass, M.; Neumann, J.; von Cramon, D.Y. Involvement of the inferior frontal junction in cognitive control: Metaanalyses of switching and Stroop studies. Hum. Brain Mapp. 2005, 25, 22-34. [CrossRef]

47. Byun, K.; Hyodo, K.; Suwabe, K.; Ochi, G.; Sakairi, Y.; Kato, M.; Dan, I.; Soya, H. Positive effect of acute mild exercise on executive function via arousal-related prefrontal activations: An fNIRS study. Neuroimage 2014, 98, 336-345. [CrossRef]

48. Braz, I.D.; Fisher, J.P. The impact of age on cerebral perfusion, oxygenation and metabolism during exercise in humans. J. Physiol. 2016, 594, 4471-4483. [CrossRef]

49. Svebak, S.; Murgatroyd, S. Metamotivational dominance: A multimethod validation of reversal theory constructs. J. Personal. Soc. Psychol. 1985, 48, 107-116. [CrossRef] 